\title{
Navigating migraine care through the COVID-19 pandemic: an update
}

\author{
Heather Angus-Leppan ${ }^{1,2}$ - $\cdot$ Angelica E. Guiloff ${ }^{3,4} \cdot$ Karen Benson $^{5} \cdot$ Roberto J. Guiloff $^{6,7}$
}

Received: 2 April 2021 / Revised: 9 May 2021 / Accepted: 10 May 2021 / Published online: 17 May 2021

(c) Crown 2021

\begin{abstract}
The worldwide treatment gap for migraine before COVID-19 inevitably widens as attention focuses on an international emergency. Migraine hits people particularly in their early and middle years, potentially reduces quality of life and productivity, and remains a common emergency presentation. This article examines the impact of COVID-19 on migraine, and changing aspects of migraine care during and after the pandemic. Many risk factors for severe COVID-19—older age, male gender, cardiac and respiratory diseases, diabetes, obesity, and immunosuppression-are less frequent in migraineurs. Telemedicine is effective for migraine follow-up, and needs ongoing evaluation. Most migraine treatments can start or continue in acute COVID-19, with care to avoid drug interactions. Close contact procedures (botulinum toxin, acupuncture and steroid injections) are avoided in lockdown or in the vulnerable. Secondary effects of COVID-19, including long COVID and its economic impact, are probably equal or greater in people with migraine. Migraine and other long-term conditions need adequate resourcing to prevent personal, social and economic suffering. Treating migraine, a sequel of COVID, potentially reduces the impact of long COVID.
\end{abstract}

Keywords COVID-19 $\cdot$ Migraine $\cdot$ Headache $\cdot$ Telemedicine $\cdot$ Long COVID $\cdot$ CGRP antagonists

\section{Introduction}

Migraine has an annual cost of $€ 95$ billion in Europe (93\% due to lowered productivity) [1], causing $9.5 \%$ of years lived with disability in 15-49-year-olds [2]. Most management occurs outside of secondary care—only 100,000 (4\%) of 2.5 million primary care headache consultations in the United Kingdom (UK) are referred to specialists [3], but headache is the fourth most common emergency department

Heather Angus-Leppan

heather.angus-leppan@nhs.net

1 Department of Clinical and Movement Neurosciences, UCL Queen Square Institute of Neurology, London WC1N 3BG, UK

2 Department of Clinical Neurosciences, Royal Free London NHS Foundation Trust, Pond Street, London NW32QG, UK

3 Northern Medical Centre, Archway, London, UK

4 Barts and the London School of Medicine and Dentistry, London, UK

5 The Crouch Hall Road Surgery, London, UK

6 Faculty of Medicine, University of Chile, Santiago, Chile

7 Imperial College Healthcare NHS Trust, London, UK presentation, $90 \%$ of which are migraine [3]. The COVID-19 (coronavirus, severe acute respiratory syndrome coronavirus 2, SARS-COV-2) pandemic creates unprecedented challenges and new working patterns for clinicians. Challenges for health practitioners and physicians and neurologists include protection of vulnerable patients, and tackling neurological complications of COVID-19. Pro-active management of long-term conditions, such as migraine and epilepsy [4], is essential to prevent suffering, secondary morbidity, particularly mental health problems, and avoidable emergency attendances $[1,2,4,5]$. A World Health Organization (WHO) survey of 155 countries found that almost half of patients with chronic diseases missed their regular medical care and medications since COVID-19 pandemic began [6].

\section{COVID-19 risks in people with migraine}

There are little specific data on migraine as a risk factor for COVID [7]. Extrapolation suggests people with migraine are at average, or lower risk, of severe acute COVID-19. COVID-19 mortality associates with cardiac and pulmonary diseases, diabetes, older age, male gender, obesity, Asian and black ethnicities and deprivation $[8,9]$. Prevalence of 
migraine in younger women militates against two of these risk factors. A UK study found migraine was most common in white women, without correlations with education or income [10] and a global review found headache disorders did not follow sociodemographic indices [2]. A meta-analysis found that migraine is more common in those with low, or very high, BMI (but not high BMI), suggesting this may be epiphenomenal rather than causal [11]. Many population studies conclude that migraineurs have a higher burden of vascular disease, which would place migraineurs at higher risk of poor COVID outcomes. Problematically, the iceberg effect in these studies identified patients with documented migraine, but much migraine is unrecorded. Prevalence rates of migraine in these female cohorts (15\%) [12] is lower than population prevalence (15 vs. $18-22 \%)$ at comparable peak migraine age [13]. In a London primary care practice of 8477 patients, migraine was also underreported. Only 494 (6\%) have documented migraine. 11/121 (9\%) with suspected COVID had recorded migraine and 1/16 (6\%) with confirmed COVID had migraine, 0/6 COVID deaths were in migraine sufferers, from March-July 2020 (KB, unpublished).

\section{The effects of COVID-19 on migraine}

Fever, sleep disturbance and dehydration with acute COVID-19 may trigger a migraine episode [14, 15]. There is little to differentiate worsening of pre-existing migraine from headaches described with COVID-19 reported in $13 \%$ of a hospitalized Wuhan cohort [16] or later studies $[17,18]$. A meta-analysis found reports of headaches in $3.5-34 \%$ of studies with a pooled prevalence of $11 \%$ and high heterogeneity [18]. Most reports with large sample size are broad-brush, lacking the granularity to differentiate whether these are migraine exacerbations, new migraine, non-specific headache associated with fever [8,
$16,17,19]$, or permutations of all three. Studies of the phenotype in COVID-9 suggest variability in semiology [20]. A Turkish web-based survey found headache in those with COVID-19 were associated with anosmia, ageusia and gastrointestinal complaints, as expected for the COVID-19 disease phenotype, but not necessarily indicative of a causal or specific relationship. Headaches were significantly more likely to be bilateral, lasting longer than $72 \mathrm{~h}$, resistant to analgesia and more common in males. They were variably described as pulsating, pressing, or stabbing in quality [21]. One study of headache in acute COVID found one-third had pre-existing migraine [22] but others report no link [21]. Headaches with COVID-19 in migraineurs were different from their usual headache in $92 \%$ of 25 studied, usually holocranial and pressing [23]. Phenotypic variations in migraine and other primary headaches are well described clinically including in individual patients [15, 24], and genetically [25].

Even before COVID-19, most migraineurs lacked professional advice, relying on over-the-counter medications [2]. A survey suggests a $60 \%$ increase in analgesia use by migraine sufferers during the pandemic [22], aligning with WHO findings of reduced medical care for people with chronic illnesses during the pandemic [6] and echoed in a Hawaiian survey [26]. Migraineurs may be particularly vulnerable to the chronic and indirect effects of the pandemic, including low mood [26], post-viral fatigue and disrupted education and childcare, increased domestic violence, and reduced income particularly affecting selfemployed, part-time zero-hour contract workers [27, 28]. $60 \%$ of 1000 Kuwaitis surveyed reported worsening of their headaches, and $80 \%$ reported anxiety and depression [22]. Other studies found that working from home during lockdown was associated with reduced stress for some migraineurs [29], and an Italian survey found quarantine had negative effects in northern Italy, but not in the south [30].

Table 1 Example of useful free resources for migraine during COVID and long COVID

\begin{tabular}{|c|c|c|}
\hline Organisation & Website & Contents \\
\hline International Headache Society & https://ihs-headache.org/en/ & $\begin{array}{l}\text { Guidelines, classification, training for profes- } \\
\text { sionals }\end{array}$ \\
\hline Migraine Trust & https://www.migrainetrust.org & $\begin{array}{l}\text { Resources and information for patients and } \\
\text { professionals }\end{array}$ \\
\hline American Headache Society & https://americanheadachesociety.org/ & $\begin{array}{l}\text { Resources and information for patients and } \\
\text { professionals, including video tutorials on } \\
\text { telemedicine }\end{array}$ \\
\hline British Association for the Study of Headache & https://www.bash.org.uk/ & $\begin{array}{l}\text { Resources and information for professionals, } \\
\text { including educational webinars }\end{array}$ \\
\hline $\begin{array}{l}\text { National Institute for Health and Care Excel- } \\
\text { lence (NICE) }\end{array}$ & $\begin{array}{l}\text { https://cks.nice.org.uk/topics/migraine/manag } \\
\text { ement/ }\end{array}$ & Migraine management guidelines \\
\hline Drug interactions and COVID-19 & https://www.covid19-druginteractions.org/ & Drug interaction charts, regularly updated \\
\hline
\end{tabular}




\section{Remote consultations in current migraine care}

Phone, video, online, and "e-consults" reduce direct COVID-19 risk to migraine patients and professionals [31]. Clinicians have rapidly upskilled to use these, usually without formal training. In many parts of the world, remote consultations are by phone. There are pockets of pre-existing high levels of telemedicine adoption and expertise [31] and freely available resources for clinicians and patients (see Table 1) [32]. Research on the long-term effectiveness of telemedicine and training in these new skills is lacking. Remote medicine is here to stay, encouraged by governments, as it is cost saving, and effective when used well. Benefits beyond COVID include patient convenience; and saved travel, time, financial and environmental costs. Problems include inability to fully examine, "digital exclusion" of vulnerable patients, and reduced non-verbal communication, particularly reduced ability to gauge mood [32]. An underexplored problem is maintaining enthusiasm, with less of the usual warmth of patient and colleague contact, flagged by a recent qualitative survey of neurologists [33].

\section{Missing the diagnosis of secondary headache}

This is a fear for both patients and healthcare workers, but the risk of missed brain tumours or other sinister causes of headache in remote consultations is low with a previous diagnosis of migraine and no change in headache features [34]. Variations on migraine not conforming to consensus definitions are sometimes tricky, such as migraine aura without headache presenting with tingling, dizziness or visual symptoms [14], all of which have a wide differential diagnosis. Clear guidance on "red flag" features must trigger urgent face-to-face assessment and investigation [35]. Most can be picked up remotely through systematic questioning (for example sudden onset, worsening or visual symptoms, scalp and temporal tenderness, jaw claudication) and patient access to thermometers and home sphygmomanometers aid assessment. In people with headache, elevated BMI and visual symptoms, urgent ophthalmological assessment is needed, looking for idiopathic intracranial hypertension as headache features may overlap with migraine [36]. Ophthalmologists and opticians have adapted safe modes of eye examination suitable for the pandemic [37]. Timely specialist advice for atypical or new-onset headaches and the need for imaging, is critical, noting the yield of headache imaging is only about $9 \%$ in unselected series [38]. Telephone and email advice, "hotlines" and urgent clinic slots allow avoidance of inappropriate emergency department attendances, and mitigates incorrect diagnoses [31].

\section{Acute migraine treatments and COVID-19 (Table 2)}

There is no evidence that triptans, paracetamol or aspirin increase the risk of COVID-19. Reports of four French COVID-19 patients taking ibuprofen with poor outcomes (Level 4 evidence) [39] triggered authorities to advise paracetamol instead of NSAIDS or aspirin for COVID-19related fever. The National Institute for Health and Care Excellence (NICE) found no relevant evidence in a rapid review of 156 potential sources [40]. Ibuprofen increases angiotensin-converting enzyme-2 (ACE-2) bioavailability, a binding site for COVID-19, and could potentially enhance initial infectivity, based on extrapolations from animal studies in cardiac muscle using sevenfold the weight-adjusted doses for humans [41]. However, NSAIDS also attenuate inflammation through reduced inflammatory cytokine activation [42]. Another proposed mechanism of harm of NSAIDs is the reduction of fever and host defence [40] implying that paracetamol and aspirin are also unsafe [40]. Informed patients can decide on ibuprofen and aspirin for their acute migraine, given the lack of definitive data.

Opioids are not indicated for migraine as they have no proven efficacy, adverse effects, are addictive and may cause analgesia overuse headache [43]. In older people, opioids increased respiratory mortality by $40-75 \%$ and some (codeine, morphine, fentanyl and methadone) are immunosuppressive [44].

\section{Preventive treatment (migraine prophylaxis)-(Table 2)}

Beta-blockers, low-dose aspirin (75 mg daily), pizotifen, and self-injected calcitonin gene-related peptide (CGRP) antagonists can be safely used during the pandemic, with no evidence that they increase COVID-19 risk or mortality. CGRP antagonist availability is limited by cost and bureaucracy in many countries.

Anti-epileptic drugs, also used on- and off-label for migraine and mood disorders, have no known impact on COVID-19 risks, but there are some cautions in migraineurs developing acute COVID while taking them. 


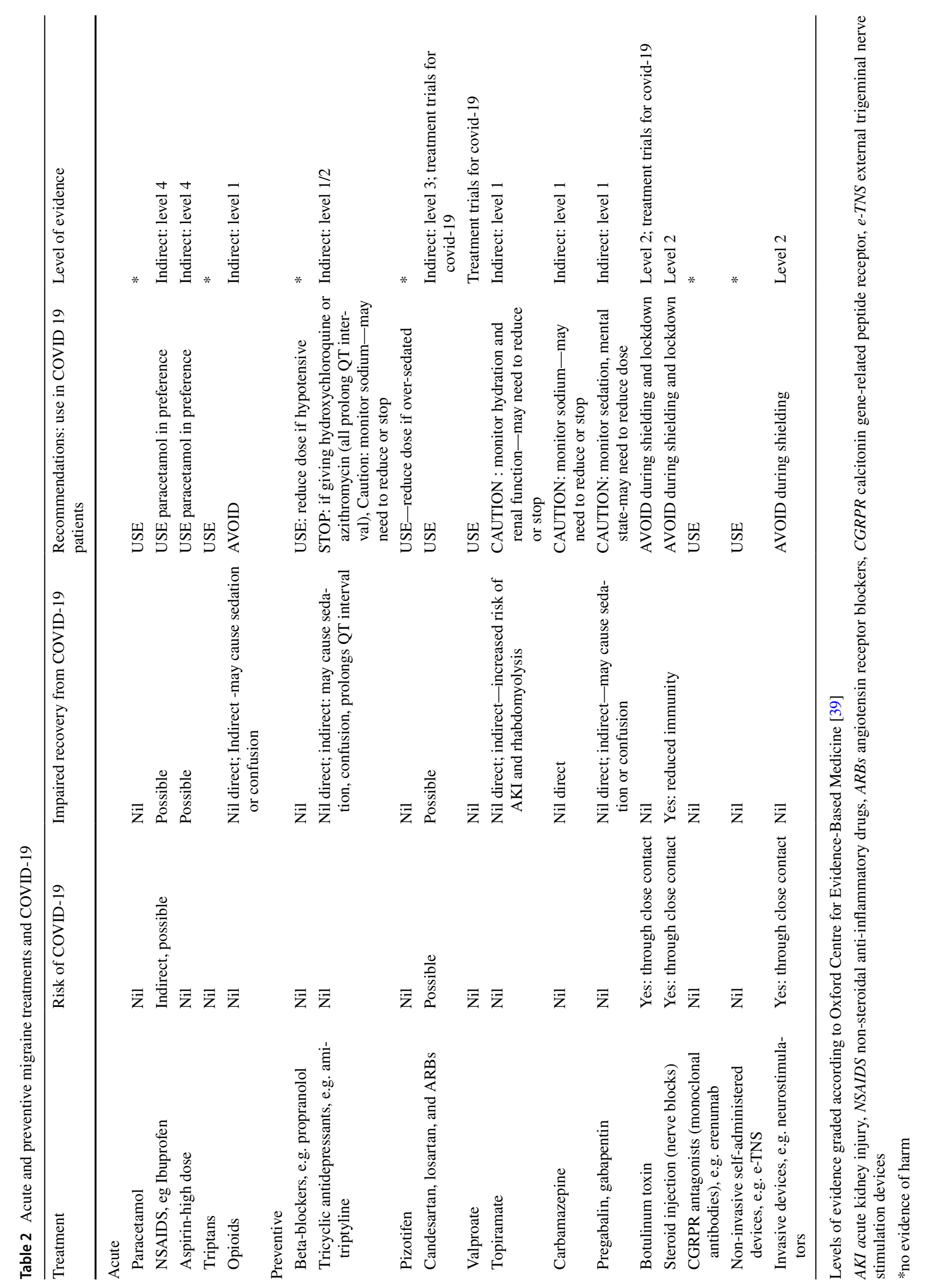


Carbonic anhydrase inhibitors such as topiramate may trigger acute kidney injury or rhabdomyolysis in dehydrated patients [45]. There are no data that valproate worsens COVID-19 outcomes, but it must be avoided if pregnancy is possible. Gabapentin and pregabalin do not increase the risks of acute COVID-19, but may cause over-sedation [46]. In older people, a study found a 1.6-fold increased risk of pneumonia on anticholinergic medication including amitriptyline or nortriptyline [47]. Whether this applies to migraineurs with acute COVID-19 is unknown. Animal studies raised theoretical concerns that ACE inhibitors and angiotensin receptor blockers (ARBs) may worsen infection, by up-regulation of ACE receptors promoting COVID-19 attachment to host membranes [48]. There are no sound human data to recommend avoiding these agents as a preventive treatment for migraine, and stopping them in those with co-morbid hypertension may cause harm. A recent population-based study in 1.4 million people found no increased mortality in COVID-19 patients taking ARBs and ACE inhibitors [49].

Procedures and invasive treatments including botulinum toxin, acupuncture, implantable neurostimulators [50] and steroid injections are avoided under lockdown conditions and in vulnerable people, because of the risks of hospital and close contact. Steroids have the additional unquantified risk of immunosuppression [51]. External Trigeminal Nerve Stimulation devices (e-TNS), such as supraorbital nerve stimulation are self-administered, safe but expensive and of disputed effectiveness [50].

\section{Treating migraine in pregnancy during COVID-19}

Only $8 \%$ of migraineurs worsen during pregnancy [52]. Greater occipital nerve block and acupuncture are usually recommended, but, during a pandemic, carry the risks of close contact. Propranolol, tricyclic antidepressants and lowdose aspirin (75-83 $\mathrm{mg}$ ) remain suitable [53].

\section{Potential treatments of COVID-19 relevant to migraine: interactions and repurposing}

Hydroxychloroquine, chloroquine and azithromycin have been investigated as preventives or treatments for COVID19. Despite little evidence, some governments recommend their use, and there is widespread self-medication. All prolong QT intervals, as do tricyclic antidepressants, commonly used for migraine, and this combination should be avoided.

Several migraine preventive therapies have been postulated from first principles and bioinformatics [54] as treatments for COVID-19. Valproic acid could potentially be repurposed for its anti-viral and anti-inflammatory actions. It inhibits viral replication by reducing RNAdependent virus RNA polymerase $[55,56]$ and cell surface binding [56]. Valproate also has systemic and pulmonary anti-inflammatory effects [55, 57]. Injection of SARS-CoV spike protein into mice worsens acute lung failure in vivo that can be attenuated by blocking the renin-angiotensin pathway, suggesting that ARBs and ACE-I are a potential therapy to prevent the cytokine storm and acute respiratory distress syndrome associated with severe COVID-19 [58, 59]. This remains of unproven efficacy against COVID-19 in humans as is use of ARBs [60]. Low-dose botulinum toxin may also attenuate the COVID-19 hyper-inflammatory response, attenuate cough and acute respiratory failure, but this is speculative at the current time [61]. Potential acute anti-viral treatments and vaccination may trigger acute migraine, but there is no evidence they exacerbate migraine long-term [62, 63].

\section{Strategies for migraine during acute and long COVID}

We face the medical and social consequences of COVID and its aftermath for people with migraine. The development of COVID-19 vaccines highlights that rapid changes are possible. For many people with migraine, education and self-help will control their condition, with emphasis on avoiding excess analgesics. There is no need to re-invent the wheel with new migraine guidelines, there are plenty (see Table 1). Analgesia overuse is a specific problem in migraine, contributing to up to $50 \%$ of chronic migraine [64]. It has increased during the pandemic [22, 26], and needs recognition, education and preventive treatment. Many people with migraine have increased depression and anxiety during COVID and treatment of this is critical to avoid a vicious spiral of worsening mental health and migraine [22]. There is a backlog of missed appointments for those most severely affected migraine patients requiring botulinum toxin and other procedures [65]. Extra specialist clinics are needed. CGRP antagonists are approved in many countries, but subject in the UK and elsewhere to a tug-of-war about who will pay for them. This is a waste of time for clinicians and disheartening for patients, and could be resolved by a standardised system with minimalistic bureaucracy[66]. Long COVID must be unpicked and there are no shortcuts to a careful analysis of the cause and best treatment of its symptoms in individuals. Systematic reviews found headache in 38-44\% of patients with long COVID [67, 68], and migraine and other headaches are frequent postdromes of viral illness 
[69] and part of chronic fatigue syndromes in $84 \%$ [70]. Treating associated migraine will potentially reduce the burden of long COVID.

\section{Conclusions}

Remote consultations can be tailored for migraine, but need attention to maintain the therapeutic relationship. Telemedicine allows screening of most secondary headache features and onward urgent referral. Current acute migraine treatments with paracetamol and triptans; and preventive treatments with pizotifen, beta-blockers, CGRP antagonists and e-TNS, can be safely started or continued during COVID. They are a key to preventing avoidable emergency consultations. There is little evidence for the concerns about use of anti-inflammatories, aspirin, ACE-inhibitors and ARBs during the pandemic. Care is needed with antiepileptic and tricyclic drugs used for migraine, which may cause sedation, renal and fluid imbalance in acute COVID-19. Addition of medications also causing QT prolongation (such as hydroxychloroquine) to tricyclics is a potential hazard. Procedures involving close contact, such as steroid injections, botulinim toxin and acupuncture, are avoided during lockdowns and in vulnerable people; leaving a backlog of patients needing treatment. The minority of people with severe migraine unresponsive to standard treatments should be offered CGRP antagonists rapidly and without bureaucratic fuss. Migraine is a treatable component of long COVID, warranting rapid research and resources. Migraine is an invisible and undertreated disability. Flexibility and action are essential to ensure sufferers have the resources and care to maximise their quality of life and their contribution to society.

Acknowledgements Patients' questions about their migraine management during the pandemic prompted the article. Two commented on concerns about NSAIDS and candesartan at the time of COVID. A patient and her family commented on the impact of severe migraine during COVID.

Author contributions HAL conceived and drafted the paper. All authors researched, discussed and finalised the article.

Funding The authors received no financial support for this research, authorship and/or publication of the article. HAL is part-funded by the NIHR.

\section{Declarations}

Conflicts of interest HAL reports research support from National Institute for Health Research (NIHR), Epilepsy Action and Royal Free Charity, and Honoraria from Eisai, Sanofi and UCB unrelated to this work. AG KB and RJG have nothing to report. None of us have been involved in, or paid for, any CGRP-antagonist related work.

Ethical approval None required.

\section{References}

1. The Work Foundation. Migraine's impact on employment in Europe. https://www.lancaster.ac.uk/work-foundation/?wpcontent/uploads/2018/04/Society\%e2\%80\%99s-headache-thesocioeconomic-impact-of-migraine.-Work-Foundation.pdf. Accessed Nov 2020

2. Global Burden of Disease Headache Collaborators (2018) Global, regional, and national burden of migraine and tensiontype headache, 1990-2016: a systematic analysis for the Global Burden of Disease Study 2016. Lancet Neurol 17(11):954-976. https://doi.org/10.1016/S1474-4422(18)30322-3

3. NHS England (2020) Improved NHS migraine care to save thousands of hospital stays. https://www.england.nhs.uk/2020/01/ improved-nhs-migraine-care/. Accessed Dec 2020

4. Martelletti P, Schwedt TJ, Lanteri-Minet M et al (2018) My Migraine Voice survey: a global study of disease burden among individuals with migraine for whom preventive treatments have failed. J Headache Pain 19(1):115. https://doi.org/10.1186/ s10194-018-0946-Z

5. World Health Organisation. Headache disorders. https://www. who.int/news-room/fact-sheets/detail/headache-disorders. Accessed Jan 2021

6. World Health Organisation. Rapid assessment of service delivery for NCDs during the COVID-19 pandemic. https://www. who.int/publications/m/item/rapid-assessment-of-service-deliv ery-for-ncds-during-the-covid-19-pandemic. Accessed Mar 2021

7. Bolay H, Ozge A, Uluduz D et al (2020) Are migraine patients at increased risk for symptomatic coronavirus disease 2019 due to shared comorbidities? Headache 60(10):2508-2521. https://doi. org/10.1111/head.13998

8. Docherty AB, Harrison EM, Green CA et al (2020) Features of 20133 UK patients in hospital with covid-19 using the ISARIC WHO Clinical Characterisation Protocol: prospective observational cohort study. BMJ 369:m1985. https://doi.org/10.1136/bmj. m1985

9. Williamson EJ, Walker AJ, Bhaskaran K et al (2020) Factors associated with COVID-19-related death using OpenSAFELY. Nature 584(7821):430-436. https://doi.org/10.1038/s41586-020-2521-4

10. Steiner TJ, Scher AI, Stewart WF et al (2003) The prevalence and disability burden of adult migraine in England and their relationships to age, gender and ethnicity. Cephalalgia 23(7):519-527. https://doi.org/10.1046/j.1468-2982.2003.00568.x

11. Gelaye B, Sacco S, Brown WJ et al (2017) Body composition status and the risk of migraine: a meta-analysis. Neurology 88(19):1795-1804. https://doi.org/10.1212/WNL.0000000000 003919

12. Kurth T, Winter AC, Eliassen AH et al (2016) Migraine and risk of cardiovascular disease in women: prospective cohort study. BMJ 353:i2610. https://doi.org/10.1136/bmj.i2610

13. Lipton RB, Bigal ME, Diamond M et al (2007) Migraine prevalence, disease burden, and the need for preventive therapy. Neurology 68(5):343-349. https://doi.org/10.1212/01.wnl.0000252808. 97649.21

14. Angus-Leppan H (2013) Migraine: mimics, borderlands and chameleons. Pract Neurol 13(5):308-318. https://doi.org/10.1136/ practneurol-2012-000502

15. Angus-Leppan H, Saatci D, Sutcliffe A et al (2018) Abdominal migraine. BMJ 360:k179. https://doi.org/10.1136/bmj.k179

16. Mao L, Jin H, Wang M et al (2020) Neurologic manifestations of hospitalized patients with coronavirus disease 2019 in Wuhan, China. JAMA Neurol 77(6):683-690. https://doi.org/10.1001/ jamaneurol.2020.1127 
17. Menni C, Valdes AM, Freidin MB et al (2020) Real-time tracking of self-reported symptoms to predict potential COVID19. Nat Med 26(7):1037-1040. https://doi.org/10.1038/ s41591-020-0916-2

18. Pinzon RT, Wijaya VO, Buana RB et al (2020) Neurologic characteristics in coronavirus disease 2019 (COVID-19): a systematic review and meta-analysis. Front Neurol 11:565. https://doi. org/10.3389/fneur.2020.00565

19. Angus-Leppan H (2001) Headache: basic trial designs, sample sizes and pitfalls. In: Guiloff RJ (ed) Clinical trials in neurology. Springer, London, pp 279-290

20. Planchuelo-Gomez A, Trigo J, de Luis-Garcia R et al (2020) Deep phenotyping of headache in hospitalized COVID19 patients via principal component analysis. Front Neurol 11:583870. https://doi.org/10.3389/fneur.2020.583870

21. Uygun O, Ertas M, Ekizoglu E et al (2020) Headache characteristics in COVID-19 pandemic-a survey study. J Headache Pain 21(1):121. https://doi.org/10.1186/s10194-020-01188-1

22. Al-Hashel JY, Ismail II (2020) Impact of coronavirus disease 2019 (COVID-19) pandemic on patients with migraine: a webbased survey study. J Headache Pain 21(1):115. https://doi.org/ 10.1186/s10194-020-01183-6

23. Membrilla JA, de Lorenzo I, Sastre M et al (2020) Headache as a cardinal symptom of coronavirus disease 2019: a crosssectional study. Headache 60(10):2176-2191. https://doi.org/ 10.1111/head.13967

24. Guiloff RJ, Fruns M (1988) Limb pain in migraine and cluster headache. JNNP 51(8):1022-1031

25. Liu A, Menon S, Colson NJ et al (2010) Analysis of the MTHFR C677T variant with migraine phenotypes. BMC Res Notes 3:213. https://doi.org/10.1186/1756-0500-3-213

26. Smith M, Nakamoto M, Crocker J et al (2021) Early impact of the COVID-19 pandemic on outpatient migraine care in Hawaii: results of a quality improvement survey. Headache 61(1):149_ 156. https://doi.org/10.1111/head.14030

27. Douglas M, Katikireddi SV, Taulbut M et al (2020) Mitigating the wider health effects of covid-19 pandemic response. BMJ 369:m1557. https://doi.org/10.1136/bmj.m1557

28. Tommasi M, Toro F, Arno S et al (2020) Physical and psychological impact of the phase one lockdown for COVID-19 on Italians. Front Psychol 11:563722. https://doi.org/10.3389/ fpsyg.2020.563722

29. Verhagen IE, van Casteren DS, de Vries LS et al (2021) Effect of lockdown during COVID-19 on migraine: a longitudinal cohort study. Cephalagia. https://doi.org/10.1177/0333102420 981739

30. Delussi M, Gentile E, Coppola G et al (2020) Investigating the effects of COVID-19 quarantine in migraine: an observational cross-sectional study from the Italian National Headache Registry (RICe). Front Neurol 11:597881. https://doi.org/10.3389/fneur. 2020.597881

31. Patterson V (2021) Neurological telemedicine in the COVID19 era. Nat Rev Neurol 17(2):73-74. https://doi.org/10.1038/ s41582-020-00438-9

32. James HM, Papoutsi C, Wherton J et al (2021) Spread, scale-up, and sustainability of video consulting in health care: systematic review and synthesis guided by the NASSS framework. J Med Internet Res 23(1):e23775. https://doi.org/10.2196/23775

33. Courtney E, Blackburn D, Reuber M (2021) Neurologists' perceptions of utilising tele-neurology to practice remotely during the COVID-19 pandemic. Patient Educ Couns 104(3):452-459. https://doi.org/10.1016/j.pec.2020.12.027

34. Headache Classification Committee of the International Headache Society (IHS) (2018) The international classification of headache disorders, 3rd edn. In: Cephalalgia, vol 38, issue 1, pp 1-211. doi: https://doi.org/10.1177/0333102417738202
35. Do TP, Remmers A, Schytz HW et al (2019) Red and orange flags for secondary headaches in clinical practice: SNNOOP10 list. Neurology 92(3):134-144. https://doi.org/10.1212/WNL. 0000000000006697

36. Wakerley BR, Mollan SP, Sinclair AJ (2020) Idiopathic intracranial hypertension: update on diagnosis and management. Clin Med (Lond) 20(4):384-388. https://doi.org/10.7861/clinmed. 2020-0232

37. Safadi K, Kruger JM, Chowers I et al (2020) Ophthalmology practice during the COVID-19 pandemic. BMJ Open Ophthalmol 5(1):e000487. https://doi.org/10.1136/bmjophth-2020-000487

38. Jang YE, Cho EY, Choi HY et al (2019) Diagnostic neuroimaging in headache patients: a systematic review and meta-analysis. Psychiatry Investig 16(6):407-417. https://doi.org/10.30773/pi. 2019.04.11

39. Oxford Centre for evidence based medicine (2011). www.cebm. net/ocebm-levels-of-evidence/. Accessed Nov 2020

40. NICE (2021) COVID-19 rapid evidence summary: acute use of non-steroidal anti-inflammatory drugs (NSAIDs) for people with or at risk of COVID-19. https://www.nice.org.uk/advice/es23/ chapter/Key-messages. Accessed Jan 2021

41. Maassen Van Den Brink A, de Vries T, Danser AHJ (2020) Headache medication and the COVID-19 pandemic. J Headache Pain 21(1):38. https://doi.org/10.1186/s10194-020-01106-5

42. Chen JS, Alfajaro MM, Chow RD et al (2021) Non-steroidal antiinflammatory drugs dampen the cytokine and antibody response to SARS-CoV-2 infection. J Virol. https://doi.org/10.1128/JVI. 00014-21

43. Tepper SJ (2012) Opioids should not be used in migraine. Headache 52(Suppl 1):30-34. https://doi.org/10.1111/j.1526-4610. 2012.02140.x

44. Dublin S, Walker RL, Jackson ML et al (2011) Use of opioids or benzodiazepines and risk of pneumonia in older adults: a population-based case-control study. J Am Geriatr Soc 59(10):18991907. https://doi.org/10.1111/j.1532-5415.2011.03586.x

45. Canel L, Zisimopoulou S, Besson M et al (2016) Topiramateinduced severe heatstroke in an adult patient: a case report. J Med Case Rep 10:95. https://doi.org/10.1186/s13256-016-0835-5

46. Tan HS, Frere Z, Krishnamoorthy V et al (2021) Association of gabapentinoid utilization with postoperative pulmonary complications in gynecologic surgery: a retrospective cohort study. Curr Med Res Opin. https://doi.org/10.1080/03007995.2021.1900092

47. Chatterjee S, Carnahan RM, Chen $\mathrm{H}$ et al (2016) Anticholinergic medication use and risk of pneumonia in elderly adults: a nested case-control study. J Am Geriatr Soc 64(2):394-400. https://doi. org/10.1111/jgs.13932

48. Mackey K, Kansagara D, Vela K (2021) Update Alert 7: risks and impact of angiotensin-converting enzyme inhibitors or angiotensin-receptor blockers on SARS-CoV-2 infection in adults. Ann Intern Med 174(2):W25-W29. https://doi.org/10.7326/L20-1446

49. Savarese G, Benson L, Sundstrom J et al (2021) Association between renin-angiotensin-aldosterone system inhibitor use and COVID-19 hospitalization and death: a 1.4 million patient nationwide registry analysis. Eur J Heart Fail 23(3):476-485. https://doi. org/10.1002/ejhf.2060

50. Miller S, Sinclair AJ, Davies B et al (2016) Neurostimulation in the treatment of primary headaches. Pract Neurol 16(5):362-375. https://doi.org/10.1136/practneurol-2015-001298

51. Gharaei H, Diwan S (2020) COVID-19 pandemic: implications on interventional pain practice-a narrative review. Pain Physician 23(4S):S311-S318

52. Negro A, Delaruelle Z, Ivanova TA et al (2017) Headache and pregnancy: a systematic review. J Headache Pain 18(1):106. https://doi.org/10.1186/s10194-017-0816-0

53. Lupi C, Negro A, Gambassi E et al (2020) Medicines for headache before and during pregnancy: a retrospective cohort 
study (ATENA study). Neurol Sci. https://doi.org/10.1007/ s10072-020-04702-0

54. Naasani I (2021) COMPARE analysis, a bioinformatic approach to accelerate drug repurposing against Covid-19 and other emerging epidemics. SLAS Discov 26(3):345-351. https://doi.org/10.1177/ 2472555220975672

55. Unal G, Turan B, Balcioglu YH (2020) Immunopharmacological management of COVID-19: potential therapeutic role of valproic acid. Med Hypotheses 143:109891. https://doi.org/10.1016/j. mehy.2020.109891

56. Pitt B, Sutton NR, Wang Z et al (2021) Potential repurposing of the HDAC inhibitor valproic acid for patients with COVID-19. Eur J Pharmacol 898:173988. https://doi.org/10.1016/j.ejphar. 2021.173988

57. Cherian SS, Agrawal M, Basu A et al (2020) Perspectives for repurposing drugs for the coronavirus disease 2019. Indian J Med Res 151(2 \& 3):160-171. https://doi.org/10.4103/ijmr.IJMR_585_ 20

58. Krishnamurthy S, Lockey RF, Kolliputi N (2021) Soluble ACE2 as a potential therapy for COVID-19. Am J Physiol Cell Physiol 320(3):C279-C281. https://doi.org/10.1152/ajpcell.00478.2020

59. Kuba K, Imai Y, Rao S et al (2005) A crucial role of angiotensin converting enzyme 2 (ACE2) in SARS coronavirus-induced lung injury. Nat Med 11(8):875-879. https://doi.org/10.1038/nm1267

60. Murthy VL, Koupenova M, Shah RV (2020) ACEing COVID-19: a role for angiotensin axis inhibition in SARS-CoV-2 infection? Circ Res 126(12):1682-1684. https://doi.org/10.1161/CIRCR ESAHA.120.317174

61. Kandasamy M (2020) Perspectives for the use of therapeutic Botulinum toxin as a multifaceted candidate drug to attenuate COVID19. Med Drug Discov 6:100042. https://doi.org/10.1016/j.medidd. 2020.100042

62. World Health Organisation. WHO Living guideline: Drugs to prevent COVID-19 [January 2021].
63. Gelfand AA, Poland G (2021) Migraine treatment and COVID-19 vaccines: no cause for concern. Headache. https://doi.org/10.1111/ head. 14086

64. Schwedt TJ, Hentz JG, Sahai-Srivastava S et al (2021) Headache characteristics and burden from chronic migraine with medication overuse headache: cross-sectional observations from the medication overuse treatment strategy trial. Headache 61(2):351-362. https://doi.org/10.1111/head.14056

65. Santos-Lasaosa S, Porta-Etessam J (2020) OnabotulinumtoxinA infiltration and nerve blocks in patients with headache and neuralgia: safety recommendations to prevent SARS-CoV-2 infection. Neurologia 35(5):291-294. https://doi.org/10.1016/j.nrl.2020.05. 004

66. Porta-Etessam J, Gonzalez-Garcia N, Matias-Guiu JA et al (2020) Should we adapt the prescription criteria for specific treatments for migraine due to the COVID-19 pandemic? Headache 60(7):1448-1449. https://doi.org/10.1111/head.13880

67. Caronna E, Ballve A, Llaurado A et al (2020) Headache: a striking prodromal and persistent symptom, predictive of COVID-19 clinical evolution. Cephalalgia 40(13):1410-1421. https://doi.org/ $10.1177 / 0333102420965157$

68. Lopez-Leon S, Wegman-Ostrosky T, Perelman C et al (2021) More than 50 long-term effects of COVID-19: a systematic review and meta-analysis. Res Sq. https://doi.org/10.21203/rs.3. rs-266574/v1

69. Rozen TD (2020) Daily persistent headache after a viral illness during a worldwide pandemic may not be a new occurrence: lessons from the 1890 Russian/Asiatic flu. Cephalalgia 40(13):14061409. https://doi.org/10.1177/0333102420965132

70. Ravindran MK, Zheng Y, Timbol C et al (2011) Migraine headaches in chronic fatigue syndrome (CFS): comparison of two prospective cross-sectional studies. BMC Neurol 11:30. https://doi. org/10.1186/1471-2377-11-30 